\title{
Atividade experimental "hands-on" para o estudo das características de um gerador (pilha voltaica) e de um recetor (voltâmetro) com material simples, de fácil acesso e baixo custo
}

Hands-on classroom experiments to study the characteristics of an electric generator (voltaic cell) and receiver (voltameter) using simple, low-cost and easy-access materials

\author{
Filipa Oliveira*1, José António Paixão ${ }^{1}$ \\ ${ }^{1}$ Departamento de Física, Universidade de Coimbra, Coimbra, Portugal
}

Recebido em 12 de Agosto, 2016. Aceito em 13 de Setembro, 2016.

\begin{abstract}
No âmbito de um amplo estudo sobre o ensino experimental da Física foram investigadas algumas causas dos problemas dos alunos portugueses nesta área. Para ajudar a solucionar estes problemas, procurámos intervir e desenvolver um conjunto de kits experimentais com vários graus de complexidade, que foram aplicados a duas amostras de estudantes (alunos da pré-seleção olímpica e alunos de escolas secundárias em Portugal). Neste artigo é apresentada uma das experiências simples destes kits "Estudo das características de um gerador (pilha voltaica) e de um recetor (voltâmetro)" que foi testada em ambiente de sala de aula, em algumas escolas. O voltâmetro é construído pelos alunos recorrendo a materiais de baixo custo e fácil acesso. Apresentamos algumas sugestões metodológicas disponibilizadas aos professores e os resultados das experiências nos grupos experimental e de controlo.

Palavras-chave: ensino experimental "hands-on", lei de Ohm generalizada, gerador e recetor elétrico, voltâmetro e motor elétrico.
\end{abstract}

As part of a comprehensive study on the experimental teaching of physics, some causes for the problems faced by Portuguese students in this area were investigated. In order to contribute to the solution of these problems, we developed a set of experimental kits with varying degrees of complexity, which were applied to two samples of students (students of the Physics Olympiads pre-selection cohort and other high school students in Portugal). This article presents one of these kits "Study of the characteristics of a generator (voltaic cell) and a receiver (voltameter)" which was tested in the classroom environment in some schools. The voltameter (electrolytic cell) is built by students using widely available, low cost materials. Some methodological suggestions made available to the teachers and the results obtained with the two sets of students are also presented.

Keywords: Experimental teaching, "hands-on", generalized Ohm's law, electric generator and receptor, voltameter and electric motor.

\section{Introdução}

A Física é uma ciência fundamental de base experimental, fazendo uso de leis e modelos matemáticos para a interpretação dos dados experimentais. Atendendo a este fato, é importante no ensino da Física a valorização da componente experimental e da aprendizagem do método científico. Alguns fenómenos e

*Endereço de correspondência: filipa.oliveira@uc.pt conceitos científicos teóricos podem ser mais facilmente assimilados se os alunos participarem com regularidade em atividades experimentais [1]. $\mathrm{O}$ ensino de base experimental facilita ainda a compreensão do modo como se produz ciência e como a experiência está na base de muitas descobertas científicas e na evolução do conhecimento.

Os alunos podem desenvolver algumas competências intelectuais e manuais (instrumentais) realizando 
atividades experimentais. A Associação Americana de Professores de Física enumera uma longa lista de objetivos de aprendizagem para as atividades laboratoriais, indicando as condições necessárias para o seu bom aproveitamento. Uma das condições é o envolvimento significativo dos alunos nestas atividades [2]. Com as experiências "hands-on" os alunos também podem manusear e manipular, o que aumenta a motivação, a concentração, a autonomia na resolução de problemas e o gosto pela ciência [3]. Nalguns países, nomeadamente nos países do norte da Europa, é posta uma ênfase particular no ensino "hands-on". Na Universidade de Helsinki, na Finlândia, por exemplo, existe o centro "Physics Teaching Resource Center Kondensaattori" onde se faz a formação de professores, com workshops e produção de recursos didáticos nesta perspetiva [4].

Em Portugal, apesar de os programas oficiais das disciplinas científicas dos ensinos básicos e secundários preconizarem a realização de experiências obrigatórias pelos alunos, constata-se que há ainda uma clara deficiência no ensino experimental das ciências, atestado, por exemplo, no desempenho dos estudantes nas Olimpíadas de Física [5]. O potencial das competições de ciência para o diagnóstico de problemas e desenvolvimento de soluções para a melhoria do ensino não está totalmente explorado. Nalguns países, os Ministérios da Educação analisam detalhadamente os resultados que os estudantes alcançam nas competições de ciência. Identificando problemas, procuram melhorar os currículos, adaptando-os ao Syllabus ${ }^{1}$ olímpico, sugerindo novas abordagens didáticas ou a lecionação de determinados temas [6-8].

Neste enquadramento, elaborámos recentemente o primeiro estudo em Portugal sobre as Olimpíadas de Física, com ênfase no diagnóstico de problemas de ensino e tendo em vista concretizar propostas de melhoria do ensino experimental da Física, em colaboração com a Sociedade Portuguesa da Física e a Escola Quark! - Escola de Física para Jovens da Universidade de Coimbra 2

No âmbito deste estudo, os professores e os alunos responderam a um inquérito no qual foram identificados alguns problemas no ensino e na aprendizagem da Física, em particular na componente experimental. Responderam 2376 alunos e 584 professores que participaram nas Olimpíadas de Física

\footnotetext{
${ }^{1}$ Programa olímpico da componente teórica e experimental. ${ }^{2}$ http://quark.fis.uc.pt/
}

em Portugal, entre 2011 e 2015. O inquérito aplicado aos professores, com trinta perguntas, era muito abrangente, procurando cobrir vários aspectos da formação académica, características do ensino experimental praticado nas escolas, formação experimental, preparação dos seus alunos para as Olimpíadas de Física, perceção da importância das Olimpíadas de Física na dinâmica da escola, e por fim, solicitavam-se sugestões para a prática de um melhor ensino experimental da Física, numa questão de resposta aberta.

Questionados sobre os principais motivos que impedem ou dificultam a realização de aulas experimentais, a falta de tempo (55\%) e de material (36\%) foram indicados pela maioria dos inquiridos. Relativamente à organização das aulas experimentais, a maioria dos professores indica que faz experiências em grupos de 3 ou mais alunos (76\%), mas um número significativo de professores refere que faz apenas aulas demonstrativas (20\%). No que diz respeita à formação dos professores, uma grande maioria (89\%) indica falta de formação específica na componente experimental, e também que a oferta formativa específica nesta área é escassa (87\%). As componentes onde os professores sentem maior carência de formação são a Física Moderna, Eletromagnetismo, Eletricidade e Eletrónica. A esmagadora maioria dos professores (99\%) valoriza o ensino experimental, embora muitos não o pratiquem com regularidade. Também segundo os professores, o interesse dos alunos portugueses pelo ensino experimental é elevado $(93 \%)^{3}$. Note-se, a este propósito, que o estudo de PISA (The Programme for International Student Assessment) 2006-2009 conclui que os alunos portugueses são dos mais interessados por ciência e que mais valorizam e ambicionam seguir carreiras científicas e tecnológicas [9].

Como resultado do fraco ensino experimental, espelhado nos inquéritos, os alunos vencedores das Olimpíadas de Física em Portugal revelam poucas competências experimentais, o que prejudica a sua prestação em provas internacionais como a $\mathrm{IPhO}$ (International Physics Olympiads) e a OIbF (Olimpíadas Ibero-americanas de Física). Tendo como objetivo contribuir para a preparação olímpica dos jovens portugueses pré-selecionados para as

\footnotetext{
3 Todos os resultados e os gráficos dos inquéritos aos professores e alunos serão publicados na tese de Doutoramento em Ensino das Ciências - ramo da Física da Faculdade de Ciências e Tecnologia da Universidade de Coimbra da primeira autora.
} 
competições internacionais, desenvolvemos, em colaboração com a Sociedade Portuguesa de Física e a Escola Quark!, um leque de atividades experimentais "hands-on" com um nível de complexidade "Olímpico", cobrindo vários temas. Para estas atividades foram desenhados guiões para alunos e documentos de apoio para os professores com sugestões metodológicas de exploração das atividades e resultados típicos. Estas atividades foram inspiradas no modelo das provas olímpicas mas fazem uso de materiais simples e de baixo custo, sendo exigido o tratamento de dados manualmente e a elaboração de gráficos de resultados em papel milimétrico, tal como nas competições internacionais, contrariando o hábito dos alunos de tratamento de dados recorrendo exclusivamente à máquina de calcular gráfica ou a folhas de cálculo no computador. Na sequência deste trabalho, foram também desenvolvidas algumas atividades mais simples que foram testadas num conjunto de escolas secundárias portuguesas, em contexto de sala de aula. Neste estudo estiveram envolvidos 311 alunos (com idades entre os 17 e 19 anos) e 9 professores de 8 escolas do ensino secundário no ano letivo de 2014/2015. Uma dessas atividades experimentais, que vamos a seguir descrever, procura estudar as "Características de um Gerador e Recetor", enquadrando-se no capítulo do programa "Eletricidade e Magnetismo" no sub-tema "Trocas de energia num circuito elétrico" [10].

\section{Metodologia}

$\mathrm{Na}$ fase do estudo que corresponde à intervenção nas escolas teve-se o cuidado de selecionar turmas de Física de $12^{\circ}$ ano de escolaridade (ano pré-universitário) com um número suficiente de alunos para poderem ser divididas em dois turnos (turno experimental e turno controlo) [11]. As atividades experimentais foram realizadas pelo mesmo professor nos turnos experimental e controlo, e foi ele que selecionou os alunos de cada turno, por ordem alfabética. No turno experimental os alunos realizaram a atividade experimental, em grupos de apenas 2 alunos, utilizando o protocolo por nós disponibilizado, com todo o material e equipamento fornecido. O tratamento de dados foi feito manualmente, os gráficos registados em papel milimétrico e o relatório feito na aula. Ao professor foi também disponibilizado um guião com sugestões metodológicas e os resultados expectáveis da atividade. No turno controlo os alunos realizaram a atividade experimental proposta pelo professor da turma, em grupos de 3 ou mais alunos, seguindo o protocolo do manual escolar e usando o material disponível na escola. O tratamento de dados e os gráficos foram realizados da forma usual, recorrendo a máquina de calcular e/ou computador, sendo o relatório feito pelos alunos em casa. Ambos os turnos realizaram, na mesma aula, um pré-teste e um pós-teste com o objectivo de avaliar conceitos científicos relacionados com a temática abordada na atividade experimental e que estavam de acordo com as orientações curriculares do Ministério da Educação português, sendo as questões colocadas no pré e pós-testes iguais. Os alunos dos dois turnos responderam a um questionário sobre as dificuldades encontradas, procurando identificar problemas de índole conceptual, operacional ou relacionados com a análise de dados. Solicitou-se ainda a todos os alunos que se pronunciassem sobre o seu interesse nesta atividade, justificando a sua resposta. Aos professores foi pedida uma análise dos aspetos positivos e negativos da aula experimental e a apresentação de sugestões.

$\mathrm{Na}$ atividade experimental "Características de um gerador e recetor" participaram 215 alunos do $12^{\circ}$ ano de escolaridade da disciplina de Física, 7 professores de 6 escolas e foram organizados 9 turnos experimentais com 9 turnos de controlo.

\section{Atividade experimental}

\subsection{Objetivos e enquadramento teórico}

As orientações curriculares do Ministério da Educação português para a atividade experimental "Características de um gerador e de um recetor" preconizam os seguintes objetivos: "Aplicar a lei de Ohm generalizada; determinar a força eletromotriz e a resistência interna de um gerador; verificar as condições em que a potência fornecida por um gerador é máxima; determinar a força contra-eletromotriz e a resistência interna de um recetor."A atividade está incluída no sub-tema "Trocas de energia num circuito elétrico", que tem os seguintes objetivos de aprendizagem (ver Tabela 1) [10]:

Os alunos deverão reconhecer que um recetor puramente resistivo converte toda a energia recebida do gerador em energia interna, isto é, usa a energia unicamente para o seu aquecimento. Se parte da energia fornecida ao recetor é transformada noutras formas de energia (química, mecânica, etc.) o recetor já não 
Tabela 1: Objetivos de aprendizagem para atividade experimental "Características de um gerador e de um recetor" Associar o gerador a um elemento do circuito que transfere energia para o circuito.

Associar o recetor a um elemento do circuito para onde é transferida energia.

Explicar o efeito de Joule com base em considerações energéticas.

Aplicar a Lei de Joule.

Interpretar o significado de força eletromotriz de um gerador, $\varepsilon$, como a energia que ele transfere para o circuito, por unidade de carga que atravessa o gerador.

Definir potência de um gerador.

Reconhecer a existência de resistência interna, $r_{i}$, num gerador e determinar a potência útil que ele pode disponibilizar para o circuito, $P_{u}=\varepsilon I-r_{i} I^{2}$.

Determinar a diferença de potencial nos terminais de um gerador, $U=\varepsilon-r_{i} I$.

Interpretar o significado de força contra-eletromotriz de um recetor, $\varepsilon^{\prime}$, como a energia que o recetor recebe e transforma noutra forma de energia, por unidade de carga que atravessa o recetor.

Reconhecer a existência de resistência interna num recetor, $r^{\prime}{ }_{i}$, e concluir que a potência transferida para o recetor é superior àquela que ele pode disponibilizar.

Determinar a diferença de potencial nos terminais de um recetor, $U=\varepsilon^{\prime}+r^{\prime}{ }_{i} I$.

é puramente resistivo. A diferença de potencial aos terminais de um recetor não puramente resistivo é sempre superior à sua força contra-eletromotriz. Um motor e um voltâmetro são exemplos de recetores não puramente resistivos abordados no programa, onde parte da energia que lhes é fornecida é transformada noutras formas de energia, para além da dissipada sob a forma de calor. Na atividade experimental o programa determina o estudo experimental de um gerador e de um recetor, sugerindo o estudo comparativo de pilhas voltaicas novas e usadas para o primeiro caso e de um pequeno motor DC, no segundo caso.

Nesta experiência optamos por usar um voltâmetro como recetor por considerarmos que tem mais vantagens que o motor em termos didáticos e pedagógicos. Muitas escolas não dispõem de motores elétricos com características adequadas e a sua aquisição é dispendiosa quando se pretende implementar este trabalho experimental com um número elevado de alunos. De fato, alguns motores usados nas escolas apresentam características não ideais, uma vez que a sua força contra-eletromotriz depende da velocidade de rotação e esta depende da tensão aplicada aos seus terminais. Nesta situação, a relação $(U, I)$ para o motor não é linear. Com o kit do voltâmetro que iremos apresentar no ponto 3.2.1 os alunos podem realizar a experiência individualmente ou em pequenos grupos. O professor pode, para além do estudo das características do recetor, explorar outros aspetos termodinâmicos e eletroquímicos do voltâmetro. O voltâmetro permite fazer a eletrólise da água, separando-a nas suas substâncias elementares, oxigénio e hidrogénio, onde a energia fica armazenada na forma de energia potencial química. É in- teressante explorar esta característica do voltâmetro intercetando conceitos de química e física.

\subsection{Material}

Para a realização da atividade experimental proposta no turno experimental foi necessário o seguinte material:

1 pilha nova de $4,5 \mathrm{~V}, 1$ pilha usada de $4,5 \mathrm{~V}, 8$ fios elétricos com "garras de crocodilos", 20 resistências de diferentes valores $(10 \mathrm{M} \Omega 1 / 4 \mathrm{~W} ; 1 \mathrm{M} \Omega 1 / 4 \mathrm{~W}$; $100 \mathrm{k} \Omega 1 / 4 \mathrm{~W} ; 5100 \Omega 1 / 4 \mathrm{~W} ; 2700 \Omega 1 / 4 \mathrm{~W} ; 560$ $\Omega 1 / 4 \mathrm{~W} ; 180 \Omega 1 / 4 \mathrm{~W} ; 150 \Omega 1 / 4 \mathrm{~W} ; 82 \Omega 1 / 2$ $\mathrm{W} ; 33 \Omega 1 \mathrm{~W} ; 22 \Omega 1 \mathrm{~W} ; 10 \Omega 5 \mathrm{~W} ; 8,2 \Omega 5 \mathrm{~W}$; $3,9 \Omega 5 \mathrm{~W} ; 2,2 \Omega 5 \mathrm{~W} ; 1 \Omega 50 \mathrm{~W} ; 0,5 \Omega 50 \mathrm{~W})^{4} 1$ interruptor, 1 voltímetro (com sensibilidade de $1 \mathrm{mV}$ ) ou multímetro, 1 amperímetro (com sensibilidade de $10 \mu \mathrm{A}$ ) ou multímetro, 1 potenciómetro de 10 $\mathrm{k} \Omega$, 1 voltâmetro, água, $10 \mathrm{ml}$ de sumo de limão, papel milimétrico.
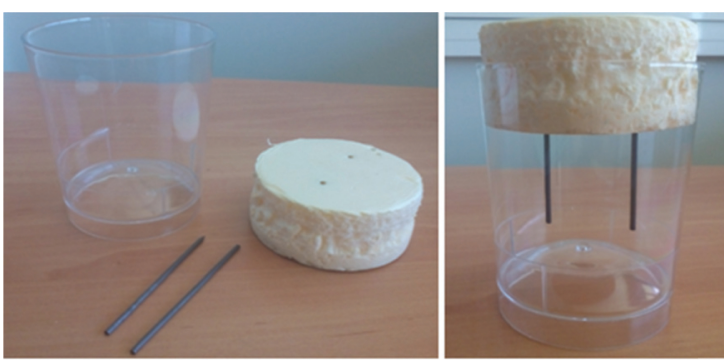

Figura 1: Construção do voltâmetro

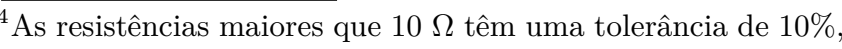
as resistências de $10 \Omega$ e as de valor mais baixo têm uma tolerância de $5 \%$. Todas as resistências fornecidas aos alunos foram calibradas.
} 


\subsubsection{Construção do voltâmetro}

Para a construção do voltâmetro foi utilizado um copo de plástico de $200 \mathrm{ml}, 2$ minas de grafite (2 mm 200HB) e uma tampa de esferovite (ver Fig. 1). As duas minas de grafite são os elétrodos e como eletrólito usou-se solução aquosa acidificada com sumo de limão (ácido cítrico).

\subsubsection{Construção das resistências com Fio de Kanthal}

As resistências comerciais de $0,5 \Omega$ e $1 \Omega$ têm um custo elevado. Por isso, foi utilizado fio de Kanthal (liga da família $\mathrm{FeCrAl}$ ) para fazer estas resistências. Este fio pode ser comprado nas lojas que vendem cigarros eletrónicos. O fio de Kanthal (de diâmetro $0,48 \mathrm{~mm}$ ) para a resistência de $0,5 \Omega$ deve ter cerca de $75 \mathrm{~mm}$ de comprimento e para a resistência de $1 \Omega$ deve ter cerca de $150 \mathrm{~mm}$ de comprimento. $\mathrm{O}$ enrolamento do fio pode ser feito em qualquer superfície cilíndrica, como por exemplo, um lápis ou uma caneta. As resistências devem ter pontas que permitam depois colocar os fios elétricos com "garras de crocodilos" (ver Fig. 2).

\subsection{Montagem, execução e análise de dados}

A montagem, a execução e a orientação para a análise de dados sugerida no protocolo experimental fornecido aos alunos foi a seguinte:

\subsubsection{Estudo das características do gerador}

Monta o circuito elétrico com a pilha nova de 4,5 $\mathrm{V}$ de acordo com a Fig. 3, usando como resistência variável a resistência de maior valor. Fecha o interruptor e regista o valor da diferença de potencial, $U$, aos terminais do gerador. Repete o procedimento anterior para as restantes 19 resistências elétricas de valores diferentes $5^{5}$ A seguir substitui no circuito elétrico a pilha nova de $4,5 \mathrm{~V}$ pela pilha usada de $4,5 \mathrm{~V}$ e repete todos os procedimentos anteriores.

Com os valores obtidos da diferença de potencial, $U$, calcula a intensidade de corrente, $I$, para cada valor das resistências usadas, quando se usa a pilha nova de $4,5 \mathrm{~V}$. A seguir constrói o gráfico de $U$ em função de $I$ em papel milimétrico. A partir deste gráfico, e aplicando a equação $U=\varepsilon-r_{i} I$, obtém os valores da força eletromotriz, $\varepsilon$, e da resistência interna, $r_{i}$, da pilha nova. Estima a incerteza nos valores obtidos. Repete, de seguida, todos os procedimentos anteriores para a pilha usada de $4,5 \mathrm{~V}$.

Constrói o gráfico da potência útil, $P_{u}$, que é a potência dissipada na resistência externa $R$ ligada à pilha nova, em função do valor de $R$ e faz o mesmo para a pilha usada de 4,5 V. Compara os gráficos e comenta os resultados. Relaciona o valor

\footnotetext{
${ }^{5}$ Nas medições com as resistências de diferentes valores tens que ser rápido para não "gastares" muito as pilhas e as resistências não aquecerem!
}

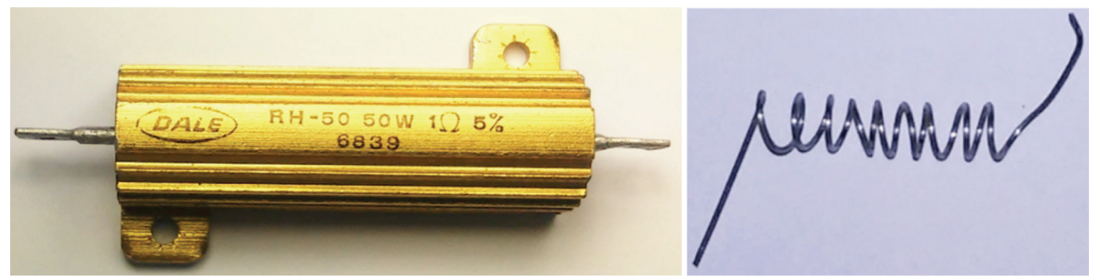

Figura 2: Duas resistências de $1 \Omega$ : à esquerda uma resistência comercial ( $50 \mathrm{~W}$, com dissipador térmico) e à direita uma resistência improvisada com fio de Kanthal
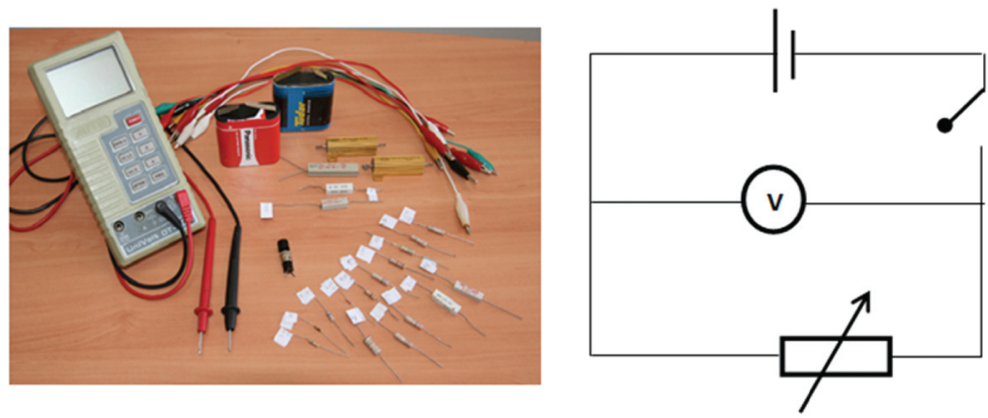

Figura 3: Circuito elétrico para o estudo das características de um gerador 
da resistência externa para a qual a potência útil é máxima com a resistência interna da pilha.

\subsubsection{Estudo das características do recetor}

Prepara o voltâmetro colocando cerca de $10 \mathrm{ml}$ de sumo de limão no interior do copo de plástico e acrescenta água quase até cima. A seguir coloca a tampa de esferovite com as duas minas de grafite. Monta o circuito elétrico com a pilha nova de 4,5 V de acordo com a Fig. 4.6

Roda devagar o potenciómetro e regista em simultâneo um conjunto de valores da intensidade de corrente, $I$, e da diferença de potencial, $U$. Tem o cuidado de selecionar as escalas mais apropriadas de medida (as correntes são de baixa intensidade, no máximo alguns $\mathrm{mA}$ ).

Constrói o gráfico de $U$ em função de $I$ em papel milimétrico. A partir deste gráfico, e aplicando a equação $U=\varepsilon^{\prime}+r_{i}^{\prime} I$, determina a força contraeletromotriz, $\varepsilon^{\prime}$, e a resistência interna, $r_{i}^{\prime}$, do recetor. Estima a incerteza nos valores obtidos.

\section{Sugestões metodológicas para os professores}

Para melhor exploração da atividade, foi fornecido aos professores um documento com um conjunto de resultados típicos e sugestões metodológicas. Apresentam-se, de seguida, algumas das mais pertinentes.

- Rever com os alunos a forma correta de ligar um amperímetro e um voltímetro num circuito elétrico. Nesta experiência podemos considerar que os instrumentos de medida são ideais (voltímetro com resistência infinita e amperímetro com resistência nula). Se forem utilizados instrumentos sem escala automática, indicar aos alunos o modo de seleção da

\footnotetext{
${ }^{6}$ Quando colocares os fios elétricos no voltâmetro tem atenção para não entornares a água com o sumo de limão e para não partires as duas minas de grafite.
}

escala mais apropriada. Os alunos deverão ser informados de que os instrumentos de medida no modo de amperímetro estão protegidos por um fusível que irá queimar numa situação de curto-circuito (por exemplo, ligando diretamente um amperímetro a um gerador). Discutir brevemente com os alunos a incerteza típica das medidas nos instrumentos usados.

- Alertar os alunos para evitarem a danificação das pilhas. Se ligarem os terminais da pilha a um fio de resistência desprezável estabelece-se um curtocircuito; a intensidade de corrente é elevada $\left(I=\varepsilon / r_{i}\right)$ e, consequentemente, a potência dissipada $\left(P=r_{i}\right.$ $\left.I^{2}=\varepsilon^{2} / r_{i}\right)$ no interior da pilha também é elevada e poderemos danificá-la irreversivelmente.

- No início das medições para o estudo das características de um gerador, questionar os alunos acerca do motivo de se iniciar a recolha de dados com as resistências de maior valor.

- Para montar o circuito da Fig. 3 é necessário efetuar quatro contatos (ligações) à resistência elétrica, usando os fios com "garras crocodilo", dois contatos para o gerador e dois contatos para o voltímetro. Para obter os melhores resultados, os contatos de ligação ao voltímetro devem ser internos aos contatos de ligação ao gerador, para evitar incluir na medida a pequena queda de tensão nestes últimos contatos.

- Quando os alunos utilizarem as resistências de $0,5 \Omega$ e de $1 \Omega$, que são enrolamentos desprotegidos de fio de Kanthal[12] (liga da família FeCrAl), alertar os alunos para não tocarem nos enrolamentos durante as medidas, pois eles vão aquecer. As medições deverão ser breves, pois quando a resistência aquece altera o seu valor e, por outro lado, o elevado valor da corrente "gasta" a pilha se o procedimento for demorado.

- Após a recolha dos dados das diferenças de potencial, $U$, para a pilha nova e para a pilha usada

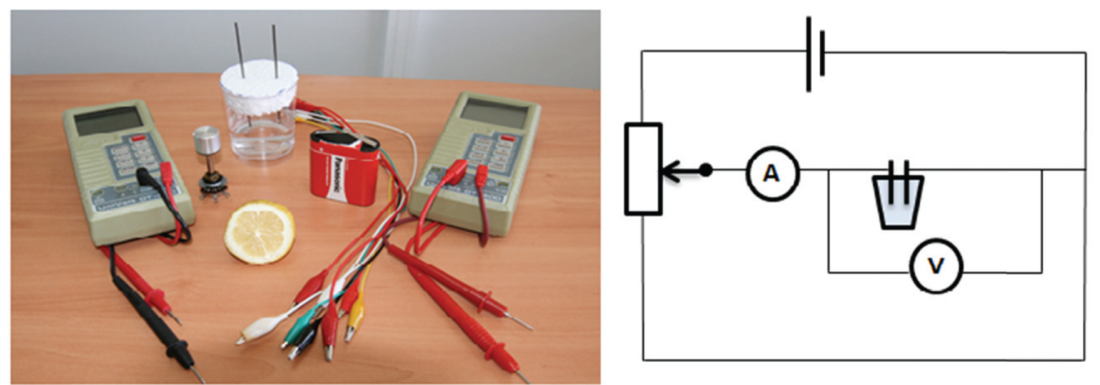

Figura 4: Circuito elétrico para o estudo das características do voltâmetro (recetor) 
quando ligadas às resistências fornecidas, os alunos deverão construir uma tabela de valores $(U, I)$, sendo a intensidade da corrente em cada medida calculada a partir dos valores das diferenças de potencial e das resistências aplicando a lei de Ohm.

- A equação $U=\varepsilon-r_{i} I$ é uma função linear $U=f(I)$, o que permite calcular os valores das características dos geradores $\left(\varepsilon, r_{i}\right)$ da pilha nova e da pilha usada através de um ajuste linear $y=$ $m x+b$ aos dados. O módulo do declive, $m$, desta reta corresponde ao valor da resistência interna e a ordenada na origem, $b$, ao valor da força eletromotriz. Se os gráficos forem feitos em papel milimétrico, estes valores podem ser obtidos diretamente dos gráficos [13].

- A partir do declive e ordenada na origem dos gráficos das Figs. 5 e 6 foram obtidos os seguintes valores:

Pilha nova: $r_{i}=1,61 \pm 0,02 \Omega ; \varepsilon=4,77 \pm 0,01$ $\mathrm{V}$,

Pilha usada: $r_{i}=824 \pm 6 \Omega ; \varepsilon=4,46 \pm 0,03 \mathrm{~V}$.

- Os alunos deverão concluir que o valor da resistência interna, $r_{i}$, na pilha usada é muito elevado comparado com o da pilha nova, enquanto o valor da sua força eletromotriz, $\varepsilon$, é apenas ligeiramente inferior ao da pilha nova.

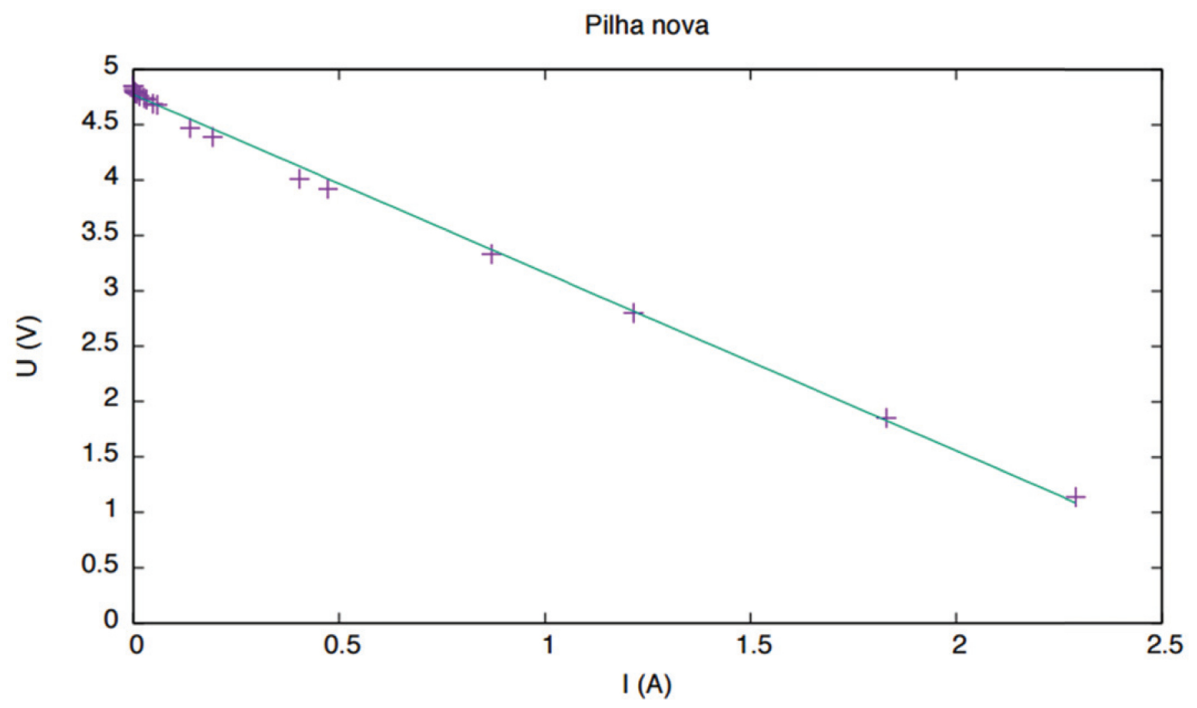

Figura 5: Gráfico da diferença de potencial, $U$, em função da intensidade de corrente, $I$, para o estudo das características de um gerador (pilha voltaica nova)

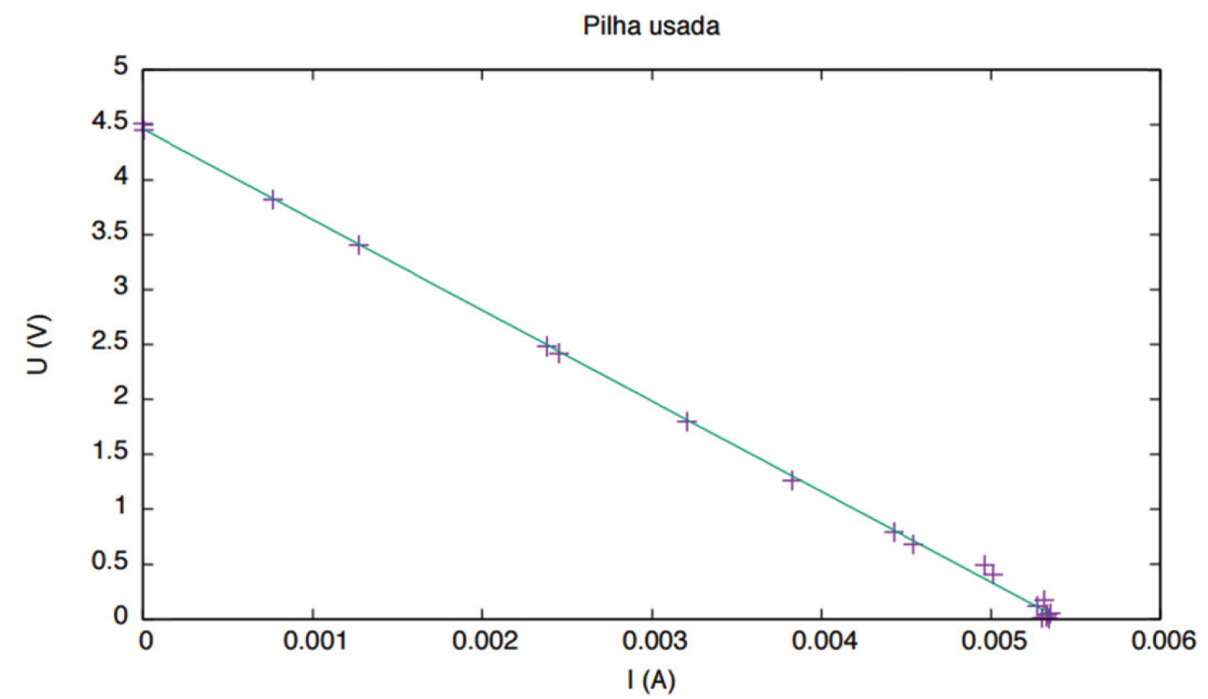

Figura 6: Gráfico da diferença de potencial, $U$, em função da intensidade de corrente, $I$, para o estudo das características de um gerador (pilha voltaica usada). Notar a diferença de escala no eixo das abcissas em relação à Fig. 5 
- Quando os alunos fizerem os gráficos da Fig. 7 e da Fig. 8 podem verificar que a potência fornecida por um gerador é máxima quando a resistência externa do circuito que este está a alimentar é igual à resistência interna do gerador [14]. Os alunos deverão ser capazes de justificar este resultado deduzindo a condição $R=r_{i}$ para o máximo da potência dissipada na resistência: $P(R)=R I^{2}=$ $R \frac{\varepsilon^{2}}{\left(R+r_{i}\right)^{2}} ; \frac{d P}{d R}=0 \Rightarrow R=r_{i}$. Para uma pilha nova a resistência externa que maximiza a potência é muito mais baixa do que para uma pilha usada, uma vez que a resistência interna da pilha aumenta com o seu uso.

- A potência máxima que uma pilha nova pode disponibilizar para o circuito é muito superior ao da pilha usada.

- No estudo das características de um recetor não puramente resistivo (voltâmetro) os alunos devem seguir o mesmo raciocínio. Com base na equação $U=\varepsilon^{\prime}+r_{i}^{\prime} I$ que também é uma função linear $U$ $=f(I)$, será possível calcular os valores das características do recetor $\left(\varepsilon^{\prime}, r^{\prime}{ }_{i}\right)$. O módulo do declive, $m$, da reta corresponde ao valor da resistência in-

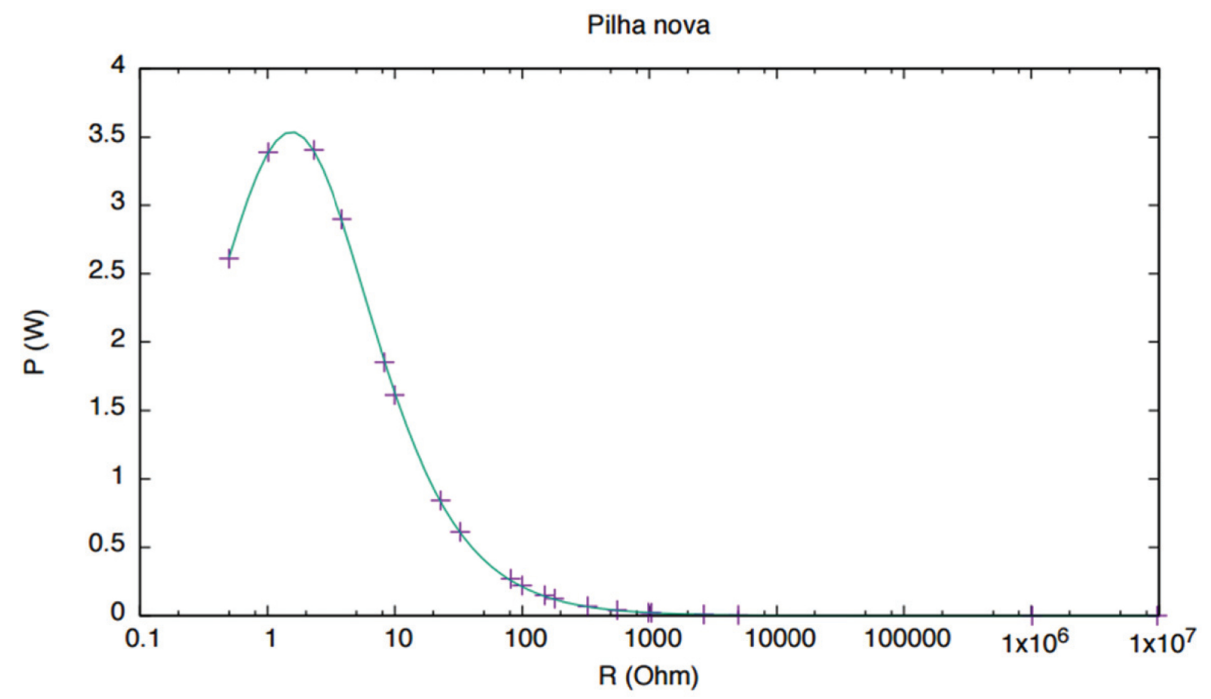

Figura 7: Gráfico da potência útil, $P_{u}$, que é a potência dissipada na resistência externa $R$ ligada à pilha nova, em função do valor $R$. A curva a cheio representa o ajuste à curva teórica $P(R)=R \frac{\varepsilon^{2}}{\left(R+r_{i}\right)^{2}}$, onde $\varepsilon=4,66 \pm 0,07 \mathrm{~V}$ e $r_{i}=1,53 \pm$ $0,01 \Omega$

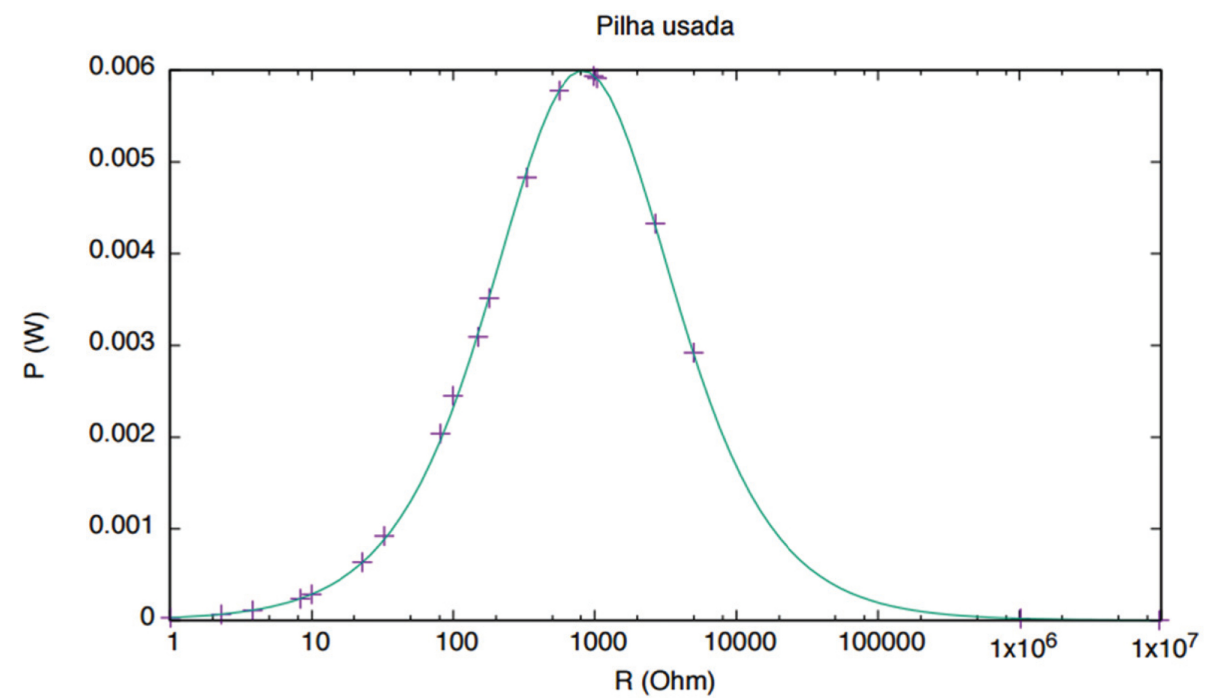

Figura 8: Gráfico da potência útil, $P_{u}$, que é a potência dissipada na resistência externa $R$ ligada à pilha usada, em função do valor $R$. A curva a cheio representa o ajuste à curva teórica $P(R)=R \frac{\varepsilon^{2}}{\left(R+r_{i}\right)^{2}}$, onde $\varepsilon=4,43 \pm 0,02 \vee$ e $r_{i}=820 \pm 7$ $\Omega$ 
terna e a ordenada na origem, $b$, ao valor da força contra-eletromotriz.

- O voltâmetro apresenta para intensidades de correntes baixas um comportamento não linear, sendo o comportamento linear observado, apenas aproximadamente, e numa região limitada de valores, para correntes mais elevadas. O modelo linear para a curva caraterística do voltâmetro é um modelo aproximado. No caso de o amperímetro não ter capacidade de medição de intensidades muito baixas $(\mu A)$ a região de comportamento não linear não será facilmente observada. A partir do gráfico da Fig. 9 e usando apenas os dados da região que exibe comportamento linear obtemos os seguintes valores para o voltâmetro: $r^{\prime}{ }_{i}=416,6 \pm 0,5 \Omega ; \varepsilon^{\prime}=2,96 \pm$ $0,01 \mathrm{~V}$.

- Quando os alunos estiverem a registar os valores para o voltâmetro chamar a atenção para as bolhas que se formam nas paredes dos elétrodos de grafite. Estas bolhas correspondem ao hidrogénio e ao oxigénio que se formam como resultado da dissociação da água. Os alunos vão verificar que as bolhas não se formam nos instantes iniciais após o circuito elétrico ser fechado mas apenas a partir de, aproximadamente, um valor de $E_{0}=1,7 \mathrm{~V}$ (potencial de dissociação da água). No gráfico da Fig. 10 é possível verificar melhor esta situação.

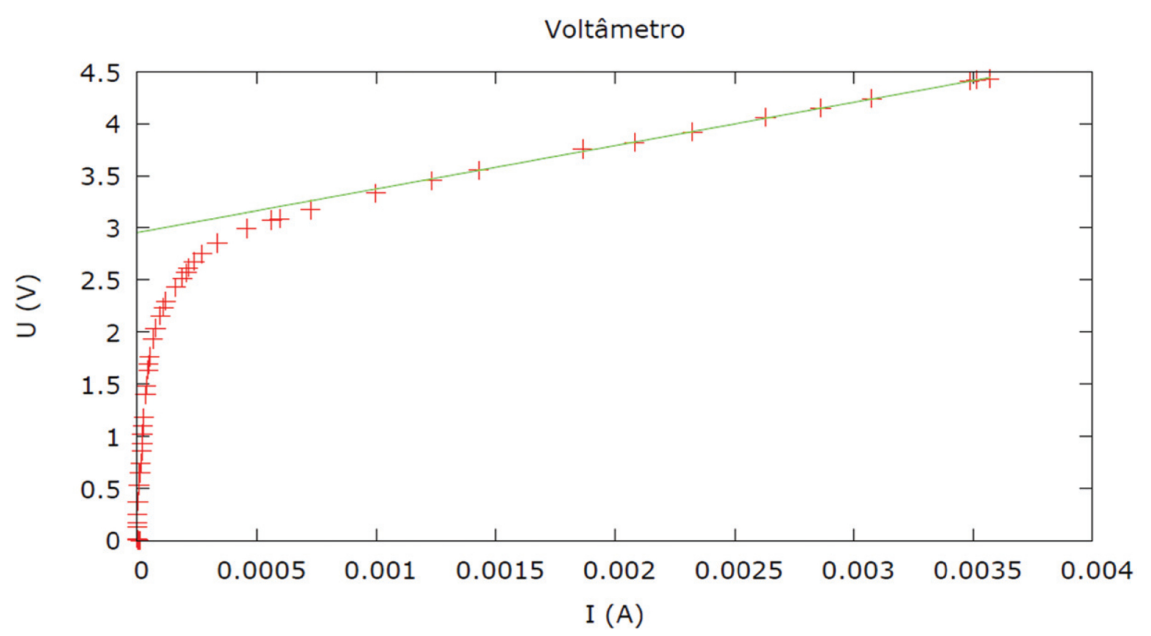

Figura 9: Gráfico da diferença de potencial, $U$, em função da intensidade de corrente, $I$, para o estudo das características de um recetor não puramente resistivo (voltâmetro)

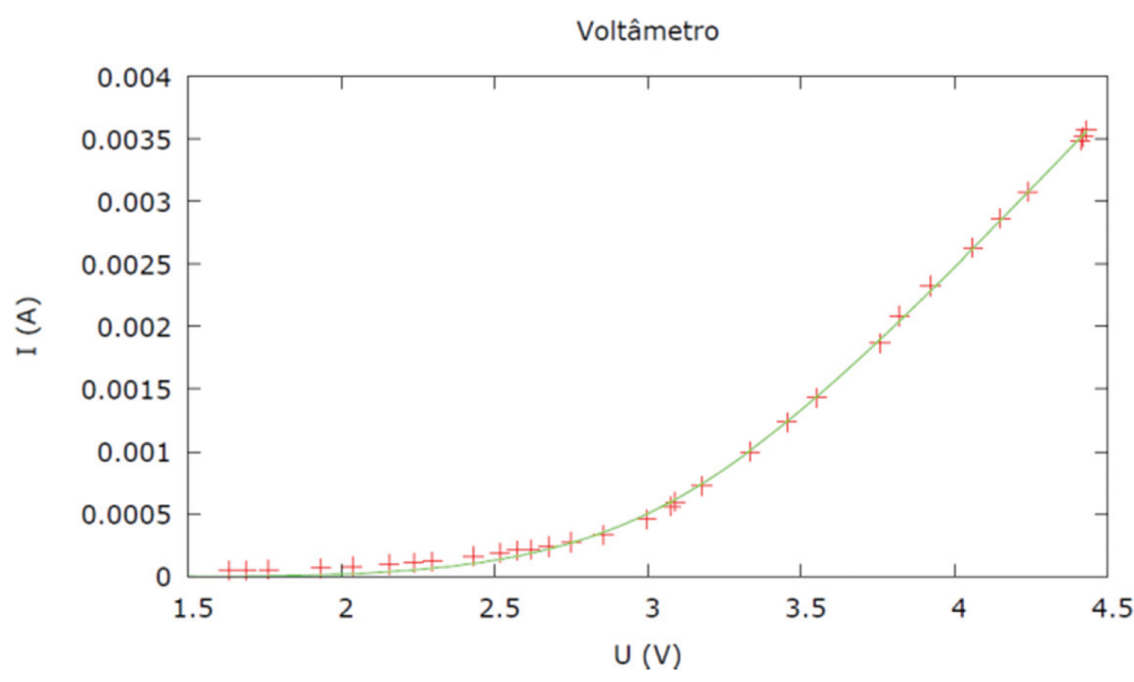

Figura 10: Gráfico da intensidade de corrente, $I$, em função da diferença de potencial, $U$, para o estudo das características de um recetor não puramente resistivo (voltâmetro). Este gráfico (Fig. 10) é o mesmo da Fig. 9 mas com os eixos das ordenadas e abcissas trocados. A linha a verde corresponde a um modelo mais sofisticado, não linear, do comportamento elétrico de uma célula eletrolítica [15]. 
- A exploração com os alunos dos aspetos termodinâmicos e eletroquímicos do voltâmetro poderá permitir uma melhor compreensão do funcionamento do voltâmetro.

- O gráfico da Fig. 11 foi obtido com um motor de corrente contínua retirado de um carro de brincar. Os alunos poderão explorar as principais diferenças e semelhanças entre o voltâmetro e o motor.

\section{Discussão dos resultados dos turnos experimental e de controlo}

Desde o início do estudo que os alunos sabiam que a classificação (0-20 valores) do pré-teste e pós-teste não contribuía para a sua nota final da disciplina de Física de $12^{\circ}$ ano. Nos pré-teste e pós-teste os alunos do turno experimental obtiveram melhores resultados (Fig. 12) talvez porque a atividade experimental proposta também explorava com mais detalhe alguns conceitos teóricos como a diferença entre as pilhas novas e usadas, a potência útil de ambas as pilhas e as características de um recetor. A montagem dos circuitos elétricos era mais pormenorizada e, como os cálculos eram feitos manualmente, também era requerida da parte dos alunos uma maior atenção nas suas tarefas para evitar erros nos procedimentos. No turno experimental, entre o pré e o pós-teste há uma subida de 3,96 valores e no turno controlo de 2,33 valores. Estas classificações baixas numa escala de 0 a 20 valores podem ser comparadas com as notas negativas dos estudantes portugueses em

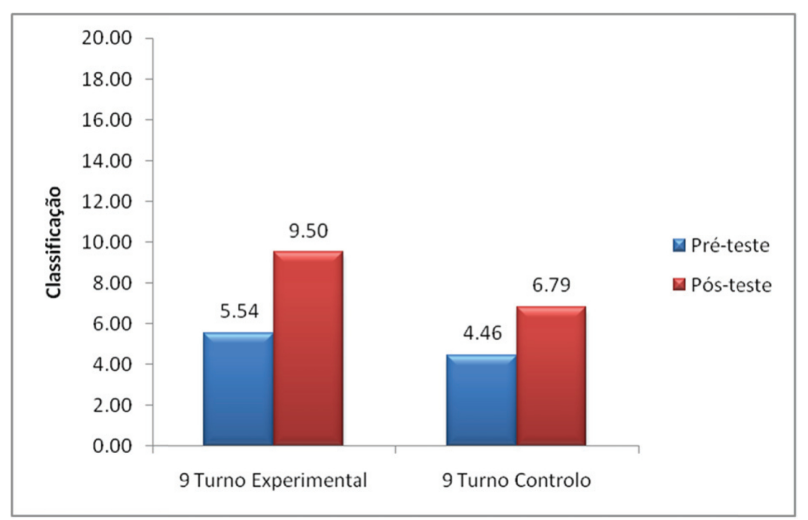

Figura 12: Resultados do pré e pós-teste: 104 alunos do turno experimental e 111 alunos do turno controlo

exames nacionais do Ministério da Educação [16]. Com ou sem imposição de avaliação os resultados na disciplina de Física dos alunos portugueses não são os melhores.

De um modo geral, os alunos de ambos os turnos mostraram interesse pela atividade experimental, sendo que a maioria classificou o seu interesse na escala de 1 a 5 entre os níveis 4 e 5 (Fig.13).

No entanto os valores dos alunos do turno experimental ultrapassam os do turno controlo no nível 4 (mais 7\%) e no nível 5 (mais 4\%). Depois de se pronunciarem sobre o interesse os alunos tinham também que justificar a sua resposta. Partilhamos algumas respostas de ambos os turnos (ver Tabela 2):

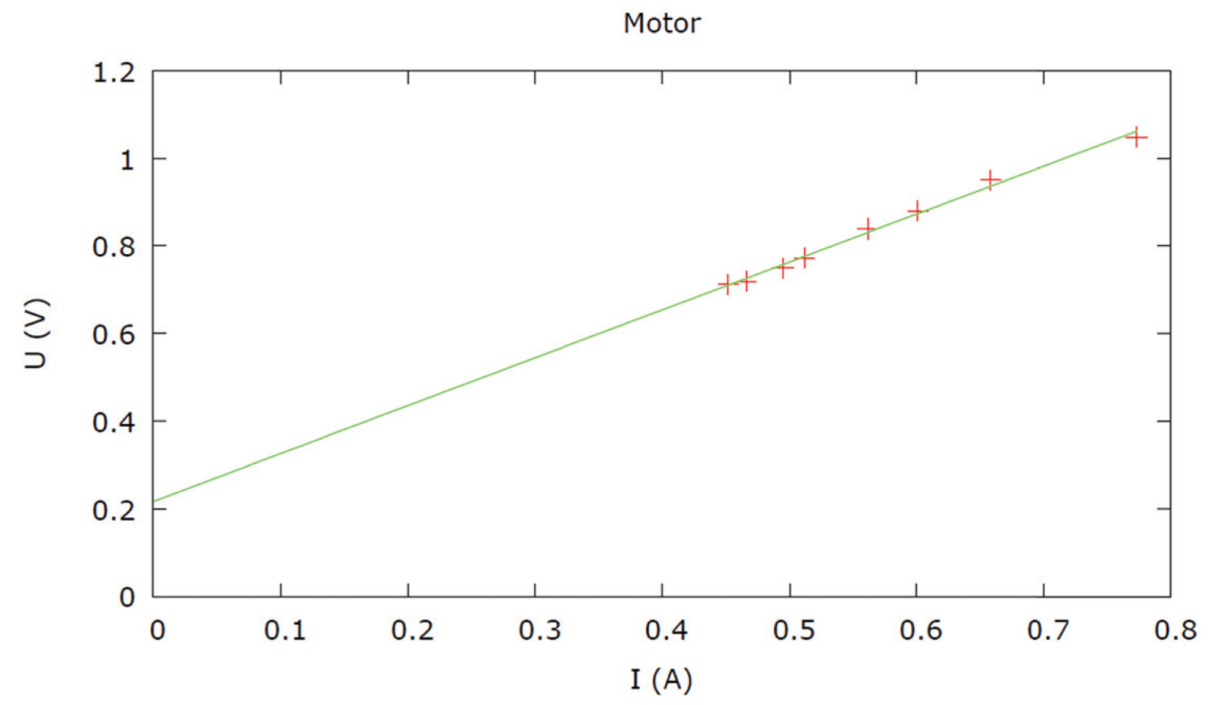

Figura 11: Gráfico da diferença de potencial, $U$, em função da intensidade de corrente, $I$, para o estudo das características de um recetor (motor de um carro de brincar). Devido ao atrito mecânico, o pequeno motor só roda para uma tensão de $\sim 0,7 \mathrm{~V}$, bem superior à sua força contra-eletromotriz 
Tabela 2: Algumas respostas dos alunos do turno experimental e do turno controlo

\begin{tabular}{ll}
\hline Turno Experimental & Turno Controlo \\
\hline "Aprendi a fazer gráficos e regressões à mão. Foi muito & "A atividade experimental ajudou-me a perceber algumas \\
positivo trabalhar sem calculadora." & coisas que eu ainda não tinha percebido." \\
\hline "Foi muito interessante fazer a atividade e comparar a pilha & "Ajudou-me a compreender melhor a utilização prática da \\
velha e a pilha nova, e observar experimentalmente o aumento & teoria nas aulas e a execução é bastante esclarecedora e fácil \\
da resistência interna com o gasto da pilha; e também fazer & de compreender." \\
a comparação entre recetores puramente e não puramente & \\
resistivos." & \\
\hline "Dado nunca ter efectuado um grande número de atividades & "É interessante ver como funciona um circuito elétrico, sem \\
laboratoriais envolvendo circuitos elétricos, achei a atividade & ser através de exercícios ou livros. Esta é uma boa forma de \\
interessante. Foi também agradável ver como é uma atividade & ensinar." \\
efetuada com um nível de rigor superior ao normal." &
\end{tabular}

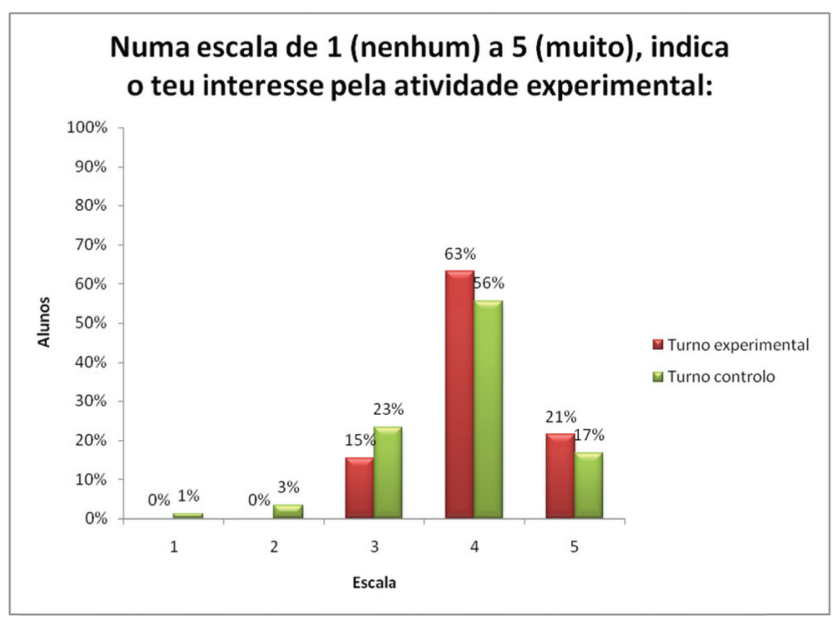

Figura 13: Avaliação do interesse pela atividade experimental

Alguns alunos do turno experimental e do turno controlo tiveram as mesmas dificuldades concetuais na compreensão das equações envolvidas na experiência, nos conceitos de potência útil, resistência interna e força eletro e contra-eletromotriz. Quanto às dificuldades operacionais, ambos os turnos apresentaram problemas a montar circuitos elétricos, a utilizar o voltímetro e o amperímetro, no manuseamento do potenciómetro (turno experimental) e do reóstato (turno controlo). $\mathrm{Na}$ análise de dados os alunos do turno experimental apresentaram mais dificuldades porque era pedido o tratamento manual dos dados e a realização dos gráficos em papel milimétrico. Na elaboração destes gráficos os alunos tinham que escolher as escalas, os eixos, as unidades e fazer a linearização da reta. Os alunos ao longo do seu percurso escolar estão muito dependentes da máquina de calcular gráfica, tendo depois dificuldades de executar manualmente este tipo de tarefas.
Os professores referiram como aspetos positivos desta atividade, o interesse e o empenho dos alunos no desenvolvimento da atividade e a possibilidade de realizar o trabalho experimental em grupos de apenas dois alunos. Tal permite descobrir as dificuldades individuais de cada aluno, o que é mais difícil com grupos numerosos. Foi ainda valorizado o trabalho com uma abordagem diferente da habitual, a disponibilização de todos os materiais e equipamentos devidamente testados e preparados para a atividade experimental, bem como os recursos metodológicos fornecidos com ênfase na abordagem "hands-on" com rigor científico, didático e pedagógico. Quanto aos aspetos negativos, referiram que os alunos demonstraram dificuldades básicas na construção manual de gráficos, na análise dos dados (retas de linearização) e em cumprir as tarefas propostas nos noventa minutos de aula. Foi ainda referido que a falta de motivação de alguns alunos para a atividade experimental poder ser devida ao fato de ela não ser contabilizada para a avaliação final. Nas sugestões, foi unânime entre os professores que esta atividade deveria ser implementada numa aula de cento e trinta e cinco minutos, que era o tempo que os professores dispunham para a realização das aulas experimentais mas que foi reduzido pelo Ministério da Educação após reformas recentes do ensino em Portugal.

\section{Conclusões}

Do extenso inquérito realizado aos professores foram colocadas em evidência algumas fragilidades no ensino experimental: falta de tempo e materiais adequados, organização das atividades em turnos demasiado numerosos de alunos, deficiências na formação dos professores e falta de oferta de 
formação em exercício profissional, sendo que as maiores dificuldades, no que diz respeito à lecionação da componente experimental, ocorrem nas temáticas de Física Moderna, Eletromagnetismo, Eletricidade e Eletrónica.

$\mathrm{Na}$ sequência deste estudo foram desenvolvidos kits experimentais com materiais simples e de fácil acesso que podem ser multiplicados nas escolas a baixo custo. Neste trabalho apresentou-se um destes kits, para o estudo das características de um gerador e recetor elétricos, e os resultados da aplicação dos kits num conjunto de escolas.

O interesse demonstrado por parte dos professores sobre o guião onde se disponibilizaram as sugestões metodológicas de exploração das atividades e resultados típicos foi grande. Este documento tornou-se uma mais-valia para o trabalho dos professores porque os ajudou a reduzir o tempo de preparação e implementação da atividade experimental. Os materiais simples e alternativos aos da escola apresentados neste trabalho também foram um aspeto muito positivo para combater a falta de material. As aulas experimentais de Física do $12^{\circ}$ ano têm uma duração de noventa minutos e, atendendo à pouca prática dos alunos em tarefas experimentais, estes necessitam de mais tempo para a sua execução. O interesse dos alunos de ambos os turnos pela atividade experimental está em consonância com o elevado interesse dos alunos portugueses pelo ensino experimental revelado noutros estudos.

Os professores manifestam nos inquéritos que a não avaliação de competências experimentais no exame nacional desvaloriza a componente experimental, talvez por este motivo não haja tanto empenho de alunos e professores no ensino experimental.

Em suma, recursos didáticos alternativos, de baixo custo, para atividades numa perspetiva "hands-on", podem ajudar a resolver alguns problemas no ensino experimental da Física.

\section{Agradecimentos}

Gostaríamos de agradecer à Sociedade Portuguesa de Física, à Escola Quark! - Escola de Física para Jovens da Universidade de Coimbra, à Ciência Viva - Agência Nacional para a Cultura Científica e Tecnológica, a todas as escolas, professores e alunos envolvidos no estudo. Ao Professor Fernando Nogueira pelos comentários ao artigo e ao Eng. Nuno Lucas do Departamento de Física da Universidade de Coimbra pela ajuda na preparação dos kits experimentais.

\section{Referências}

[1] A. Ornstein, Journal of Science Education and Technology 15, 285 (2006).

[2] American Association of Physics Teachers, Role of Labs in High School Physics, disponível em http://www.aapt.org/resources/policy/ Role0fLabs.cfm acessado 25 de julho de 2016.

[3] L. Haury and P. Rillero, Perspectives of Hands-On Science Teaching, North Central Regional Educational Laboratory's, disponível em http://files. eric.ed.gov/fulltext/ED372926.pdf, acessado em 25 de Julho de 2016.

[4] J. Jauhiainen, J. Lavonen, I. Koponen and K. KurkiSuonio, Physics Education 37, 128 (2002).

[5] F. Nogueira, Gazeta de Física 33, 35 (2010).

[6] F. Redish, J. Saul and R. Steinberg, Americal Journal of Physics 66, 212 (1998).

[7] W. Gorzkowski, International Physics Competitions: International Physics Olympiads and First Step to Nobel Prize in Physics, editado por Waldemar Gorzkowski (Instytut Fizyki PAN, Warszawa, 1999), p. 7-24, disponível em http://www.jyu.fi/kastdk/ olympiads/history.pdf, acessado em 25 de julho de 2016.

[8] Z. Rajkovits and L. Markovich, Physics Competitions 6, 64 (2004).

[9] PISA (2006): Science Competencies for Tomorrow's World. Volume 1: Analysis. (OECD, Paris, 2007), p. 129, disponível em http://dx.doi.org/10.1787/ 9789264040014-en, acessado em 25 de julho de 2016.

[10] E. Cardoso, G. Ventura, J.A. Paixão, M. Fiolhais, M.C.A. Sousa e R. Nogueira, Programa de Física $12^{\circ}$ Ano - Curso Científico - Humanistico de Ciências e Tecnologia (Ministério da Educação, Lisboa, 2004), p. $58-59$ e p. $68-70$.

[11] B. Tuckman, Manual da Investigação em Educação (Fundação Calouste Gulbenkian, Lisboa, 2000).

[12] Kanthal A-1, disponível em http://www.kanthal com/en/products/material-datasheets/wire/ resistance-heating-wire-and-resistancewire/kanthal-a-1/, acessado em 29 de Julho de 2016.

[13] G.L. Squires, Practical Physics (Cambridge University Press, Cambridge, 2001), 4th ed, p. 133-142.

[14] LD Physics Leaflets, Determining the Internal Resistance of a Battery, disponivel em http://www.lddidactic.de/literatur/hb/e/p4/p4111_e.pdf, acessado em 25 de Julho de 2016.

[15] S. Muzhong, B. Nick, D. Yulong and S. Keith, International Journal of Hydrogen Energy 36, 14335 (2010). 
[16] Processo de Avaliação Externa da Aprendizagem, Provas Finais de Ciclo e Exames Nacionais 2014, editado por A. Monteiro, D. Fonseca, E. Rodrigues, I. Monteiro, I. Rebelo, M. Silva, R. Ferreira e L.P. dos Santos (Ministério da Educação e Ciência de Portugal, Lisboa, 2014), p. 65, disponível em http://www.dge.mec.pt/sites/default/ files/JNE/relatorio_anual_do_jne_2014.pdf acessado em 28 de julho de 2016 . 